\title{
METHODS FOR ESTIMATION OF OPTICAL FIBER NON-LINEARITY USING SELF-PHASE MODULATION EFFECT
}

\author{
A. Supe, J. Porins \\ Institute of Telecommunications, Riga Technical University, \\ 12 Azenes Str., LV-1048, Riga, LATVIA \\ e-mail: jurgis.porins@rtu.lv
}

\begin{abstract}
Due to ever increasing channel density in WDM systems the nonlinear optical effects in fibers become a limiting factor for the high-speed data transmission, which necessitates determination of such important characteristic as the coefficient of optical nonlinearity. To measure it, two methods are proposed: continuous wave self-phase modulation (CW-SPM) and pulse phase self-modulation (P-SPM). The research work has been carried out both in the form of calculations and experimentally, taking as wavelength the central one from the third optical transparency window, $\lambda=1550 \mathrm{~nm}$. Based on the OptSim 5.2 simulations and experimental results, the sought-for nonlinear coefficients have been calculated. In the paper, comparative analysis and estimation of the results are performed for two different optical fibers.
\end{abstract} effects.

Key words: fiber effective area, nonlinear coefficient, nonlinear optical

\section{INTRODUCTION}

The fiber optic transmission systems (FOTS) extensively used now worldwide stem from the development of two main technological directions. First of them is obtaining of low-loss $\mathrm{SiO}_{2}$ fibers, whereas the other is development of corresponding high-speed $(R>10 \mathrm{Tbit} / \mathrm{s})$ optical devices (e.g. semiconductor lasers, light diodes, etc.) [1]. In the past years, owing to cooperation of physicists and chemists, new fiber types with low dispersion and attenuation have been obtained, which are used in long haul FOTS and local area networks (LANs). Nowadays, the fiber optics is employed not only for creation of global and local computer networks but also for a private network's needs; at the same time, the rapid increase in the power put into an optical fiber (OF) gives rise to such side phenomena as nonlinear optical effects (NOEs). Therefore, when planning and designing high speed $(R>1 \mathrm{Gbit} / \mathrm{s})$ FOTS in which new single-mode fibers (SMFs) and standards are employed it is necessary to perform a preliminary estimation of their operation and the NOEs in order to reduce their influence.

Ideally, the OF used in communication technologies should not possess a high nonlinearity coefficient; however, the nonlinear phenomena can be observed at very high intensities of light and large transmission distances [1]. Although the power used at transmission of signals is not very high - several (or a couple of tens at most) microwatts - the light intensity in a fiber is very high [2]. This is owing to the fact that the cross-section of OFs employed in the communication technologies is very small $-10^{-7}-10^{-8} \mathrm{~cm}^{2}$ for a single-mode fiber, so the light intensities acting 
upon a fiber reach as much as several $\mathrm{GW} / \mathrm{cm}^{2}$. Such an intensity value is sufficient for inducing nonlinear effects, thus adversely influencing the light propagation in a fiber.

\section{NONLINEAR CHARACTERISTICS OF OPTICAL FIBER}

An optical fiber is characterized by nonlinear properties. The most significant of its parameters are the nonlinear refraction index and the effective cross-section area, $A_{\text {eff }}[1,3]$. The majority of NOEs arise in a fiber owing to nonlinear refraction, since at high light intensities the OF refractive index is determined by its dependence on the intensity:

$$
n=n_{0}+n_{2} I=n_{0}+n_{2} \frac{P}{A_{\text {eff }}},
$$

where $n_{0}$ is the linear refractive index;

$n_{2}$ is the nonlinear refractive index;

$I$ is the light radiation intensity;

$P$ is the maximum radiated power.

The nonlinearity effect in an OF is rising with intensity, which, in turn, is inversely proportional to its core area. The light radiation power spreads nonuniformly over the OF core cross-section. It is greater along the OF central axis and decreases towards the core/cladding interface. When spreading, this power is even pressing into the covering, following the real profile of the OF refractive index. The OF cross-section area is very significant for NOE manifestation; therefore it is necessary to know the distribution of light radiation power in a fiber. Due to non-uniform propagation of radiation in the fibers, communication technologies employ the effective cross-section area, $A_{\text {eff. }}$. The corresponding definition takes into account the OF cross-section area and the intensity distribution over it. In the general case, this parameter is defined as [1]

$$
A_{e f f}=\frac{\left(\iint_{-\infty}^{\infty}|F(x, y)|^{2} d x d y\right)^{2}}{\iint_{-\infty}^{\infty}|F(x, y)|^{4} d x d y},
$$

where $F(x, y)$ is the electric field mode distribution in a fiber.

It is evident that $A_{\text {eff }}$ is dependent on such OF parameters as the core radius and the difference in the core and cladding refractive indices. For a standard singlemode fiber we can approximate $F(x, y)$ with Gaussian distribution. Then the effective cross-section area can be expressed as

$$
A_{e f f}=\pi w^{2},
$$

where $w$ is the mode width parameter.

This approximation cannot be applied to a fiber whose refractive index profile is not step-like, for example, to a dispersion-shifted fiber (DSF). Depending on the OF type and producer, the $A_{\text {eff }}$ value usually varies in the range from 20 to $100 \mu \mathrm{m}^{2}$ at the wavelength of $1.5 \mu \mathrm{m}$. Besides, fibers with a large effective area are 
also produced to reduce the optical radiation intensity and, accordingly, the OF nonlinearity $[1,4]$.

Another parameter characterizing the OF nonlinearity is the nonlinear phase shift $\phi_{N L}$, which depends on the OF length $L$ and its effective length, with $L_{\text {eff }}<L$ owing to losses $\alpha$. The $L_{\text {eff }}$ parameter is introduced to calculate the fiber area where most of the NOE interactions occur, and is defined as [1]

$$
L_{e f f}=\frac{1-e^{-\alpha L}}{\alpha} .
$$

The phase maximum is found from the relationship [5]:

$$
\phi_{\max }=L_{\text {eff }} / L_{N L}=\gamma P_{0} L_{e f f},
$$

where $L_{N L}$ is the OF nonlinear length;

$P_{0}$ is the power;

$\gamma$ is the nonlinear coefficient.

In turn, the nonlinear coefficient is expressed as $[1,6]$

$$
\gamma=\frac{2 \pi n_{2}}{A_{e f f} \lambda} .
$$

From relationship (6) the physical sense of $L_{N L}$ follows as the effective propagation length at which $\phi_{\max }=1$.

In order to determine $n$ at high intensities it is necessary to compare this coefficient with some constant value. For this purpose the nonlinear coefficient is expressed as

$$
\gamma=\frac{2 \pi \cdot n_{2}}{\lambda_{s} A_{\text {eff }}} .
$$

In this expression, $\lambda_{s}$ is the signal wavelength in vacuum. The determination of refractive index $n_{2}$ is usually done after measuring $A_{\text {eff }}$ and $\gamma$ and then calculating $n_{2}[7]$.

\section{MEASUREMENTS OF FIBER EFFECTIVE AREA}

All nonlinear effects related to the Kerr effect depend on the electromagnetic field intensity in the relevant environment. However, usually the total optical power at a fiber's input and output is measured, with the latter being merely the integral of the intensity distribution over the entire area of a fiber's crosssection. As mentioned previously, the optical radiation is not distributed uniformly in a single-mode fiber. Besides, it does not fill completely the whole fiber's volume. This field is stronger along the central longitudinal axis of the fiber and decreases in the direction to the core-cladding interface, forcing into the cladding in dependence on the real profile of a fiber's refractivity. Therefore, the $A_{\text {eff }}$ parameter is indeed very significant for the NOE. Similarly as in Eq. (2) we can express it as 


$$
A_{\text {eff }}=\frac{2 \pi\left(\int_{0}^{\infty}\left|E_{a}(r)\right|^{2} r d r\right)^{2}}{\int_{0}^{\infty}\left|E_{a}(r)\right|^{4} r d r}=\frac{2 \pi\left(\int_{0}^{\infty} I(r) r d r\right)^{2}}{\int_{0}^{\infty} I^{2}(r) r d r},
$$

where $E_{a}(r), I(r)$ are the amplitude and the intensity, respectively, of the near field of the fundamental mode at a distance of radius $r$ from the central longitudinal axis of the fiber $[8,9]$.

In this investigation, effective area was determined through the transversal shift measurements. This - the so-called far-field distribution measurement method - is based on a transversal shift of two fiber ends using a micro-positioner to perform the key operations: positioning of the optical fiber and its shifting in the direction perpendicular to its longitudinal axis. The transition of optical power from the source fiber's central mode to the same mode of the receiving one is described by integrating over the area, i.e. by the relationship:

$$
C(u)=\iint_{S} E_{a}(|r|) E_{a}(|r-u|) d r,
$$

where $u=|u|$ is the shift from the fiber's central axis.

The integrals are taken over the entire area $(S)$ where both the fibers' modes are overlapping.

Integral (9) can be written in polar coordinates, i.e.:

$$
C(u)=\int_{0}^{2 \pi} \int_{0}^{\infty} E_{a}(r) E_{a}\left(r^{\prime}\right) r d r d \theta=\left[E_{a}(r) * E_{a(r)}\right]_{r=u}
$$

where $r^{\prime 2}=u^{2}+r^{2}-2 r u \cos (\phi)$, and $*$ denotes a two-dimensional Henkel transformation convolution described by the expression:

$$
H\{C(u)\}=H\left\{E_{a}(r) * E_{a}(r)\right\}=F^{2}(p)
$$

Here $F^{2}(p)$ is the far-field power distribution in a fiber.

Using Eqs. (9) and (10), the power $C^{2}(u)$ transferred from one fiber to the other can be obtained for the central mode of the near-field power distribution by calculating it through the far-field one $[9,10]$. Further, the effective area can be obtained using the near-field distribution.

In the measurements, it is necessary that the both fibers' ends be fully identical, since they should be placed precisely opposite to each other. The placement of the fibers on parallel planes was done by fixing them by fasteners arranged in parallel, each fiber by its opposite parallel fastener. One of the fasteners is immovable, securing the fiber with an optical radiation source at its second end. The second (receiving) fiber is placed on a movable platform, whose position can be varied by three stepping motors. Therefore, the receiving fiber could be centered against the source fiber thus allowing achievement of the 
maximum power for the transmitted optical signal. Actually, a connection of two fibers ends is formed, and, by varying the position of one of the fibers we can obtain the maximum transmitted power. As a result of measurements, the far-field power distribution in a fiber's cross-section has been obtained. Then it was necessary from this distribution to derive the near-field power distribution, and, finally, to calculate the value of the fiber's effective area. The measurement setup (Fig. 1) contains a laser source tunable for the 1520-1630 nm and 1465-1575 nm ranges. Such a laser allows for transmitting via a fiber the optical radiation with the signal power up to $+13 \mathrm{dBm}(20 \mathrm{~mW})$. For measuring the optical power, at the optical connection output a meter of power and wavelength is placed.

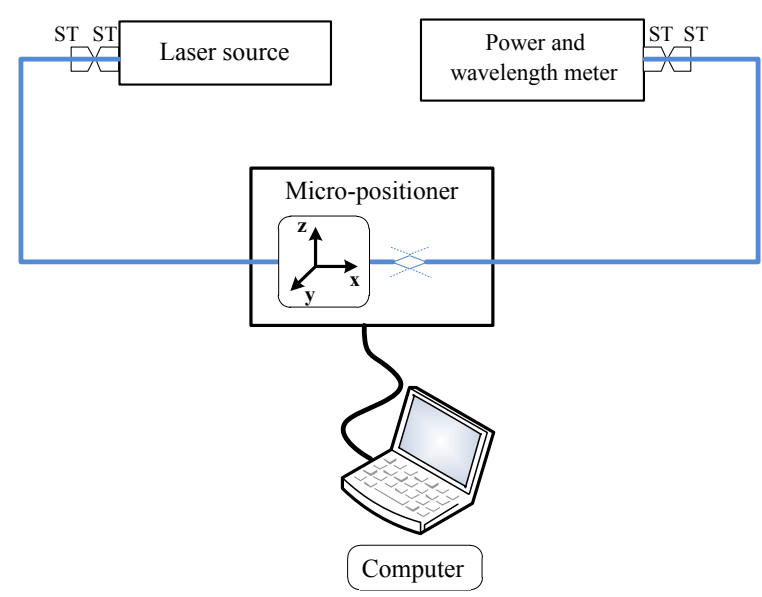

Fig. 1. The block diagram of $A_{\text {eff }}$ measurement scheme.

In our experiment, the measurements were taken at three different optical signal wavelengths. The purpose of such variations was to study the dependence of the effective area on this parameter. The results of measurements for G.652 D type fiber are shown in Fig. 2.

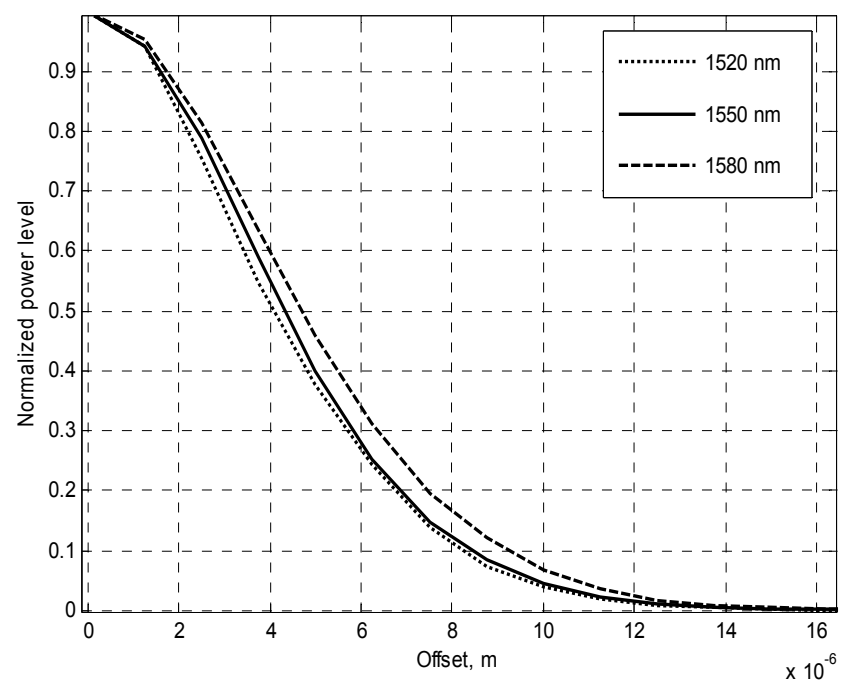

Fig. 2. Measured fiber cross-section for three wavelengths: 1520, 1550 and $1580 \mathrm{~nm}$. 
Based on the results of measured power distribution and on the model for their processing described previously, the fiber's effective area values have been calculated. Table 1 presents these values obtained using our own script in the MatLab software.

Table 1

The effective area of G652 D and G655 C optical fibers

\begin{tabular}{|r|c|c|}
\hline \multirow{2}{*}{$\lambda, \mathrm{nm}$} & \multicolumn{2}{|c|}{$A_{\text {eff, }}, \mathrm{m}^{2}$} \\
\cline { 2 - 3 } & $\mathrm{G} 652 \mathrm{D}$ & $\mathrm{G} 655 \mathrm{C}$ \\
\hline 1520 & 62.39 & 53.12 \\
\hline 1550 & 65.76 & 54.19 \\
\hline 1580 & 64.79 & 59.03 \\
\hline
\end{tabular}

The $A_{\text {eff }}$ dependence on the wavelength for the two types of fibers is shown in Fig. 3.

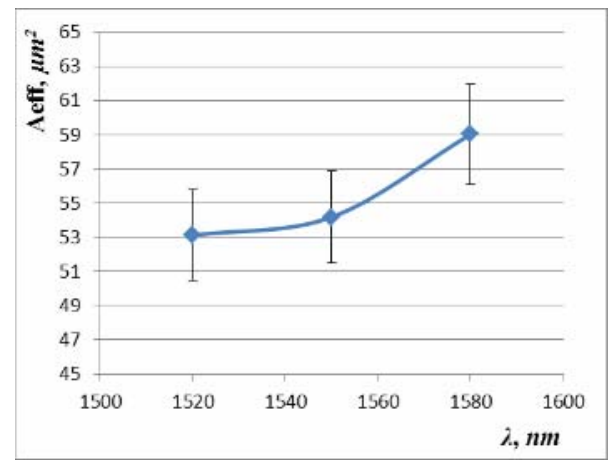

Fig.3. a) Effective area results for G652 D type fiber.

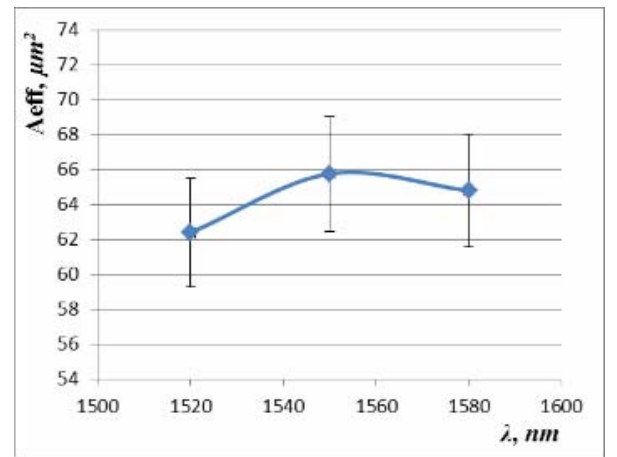

Fig.3. b) Effective area results for G655 C type fiber.

The effective area of a standard ITU-T G.652 D single-mode fiber is evenly increasing at larger wavelength. We can therefore conclude that the optical signal intensity at larger wavelength decreases. Results for G655 C type fiber show similar tendency. However, as could be seen, the effective area value is decreasing at $\lambda=1580 \mathrm{~nm}$, which possibly is due to a measurement error: as error bars show, the actual value of $A_{\text {eff }}$ can be located around this point. Detailed analysis of measurement uncertainty calculations is given in the penultimate section of this publication.

\section{EXPERIMENTAL AND SIMULATION SCHEMES FOR DETERMINATION OF NON-LINEAR COEFFICIENT}

To determine coefficient $\gamma$ for different OF types various methods are offered - both interferometric and non-interferometric $[5,11]$. In this research we used two non-interferometric methods (continuous-wave self-phase modulation (CW SPM) and pulse phase self-modulation (P-SPM)), with better results - compared simulations and experiments - obtained by the P-SPM method. At the same 
time, the advantage of CW-SPM technique is that it does not need using a separate pulse source but a continuous wave laser instead.

Both the simulation and the experimental scheme (Fig. 4) employ one optical channel. A high-power tunable laser source (the wavelength resolution of $1 \mathrm{pm}$, the FWHM (full-width-at-half-maximum) of $50 \mathrm{MHz}$, the reference wavelength $\lambda=1550 \mathrm{~nm}$ ) is continuously switched on. In the CW-SPM case, laser radiation is directly sent to the OF, whereas for P-SPM the optical signal is modulated using external intensity modulation (IM). For this purpose we employed an electro-optic Mach-Zehnder modulator (MZM) with the pseudo-data $9.953 \mathrm{Gbps}$ pulse sequence output of a pulse pattern generator (PPG). The MZM optical insertion loss by $9.953 \mathrm{Gbps}$ is $<5 \mathrm{~dB}$. The signal is amplified by an erbium-doped fiber amplifier (EDFA). After amplification, the signal is sent to different type fibers (G.652 standard single mode fiber (SSMF) and G.655 C standard dispersion shifted fiber (DSF)), where optical pulses are propagating over a $1 \mathrm{~km}$ [6]. Fiber dispersion and effective area parameters are given in Table 2.

Table 2

G652 D and G655 C type fiber parameters

\begin{tabular}{|l|l|l|}
\hline \multicolumn{1}{|c|}{ Fiber type } & \multicolumn{1}{c|}{ G652 D } & \multicolumn{1}{c|}{ G655 C (DSF) } \\
\hline Dispersion, $\mathrm{ps} /(\mathrm{nm} \cdot \mathrm{km})$ & $\leq 18(\lambda=1550 \mathrm{~nm})$ & $\leq 5(\lambda=1550 \mathrm{~nm})$ \\
\hline$A_{\text {eff }} \mu \mathrm{m}^{2}$ & 65.76 & 54.19 \\
\hline
\end{tabular}

The simulations were performed using OptSim 5.2 software. The method of calculation is based on solving a complex set of differential equations, taking into account optical and electrical noise as well as linear and nonlinear effects. The time domain split step (TDSS) method was applied to simulate linear and nonlinear behavior for both optical and electrical components.

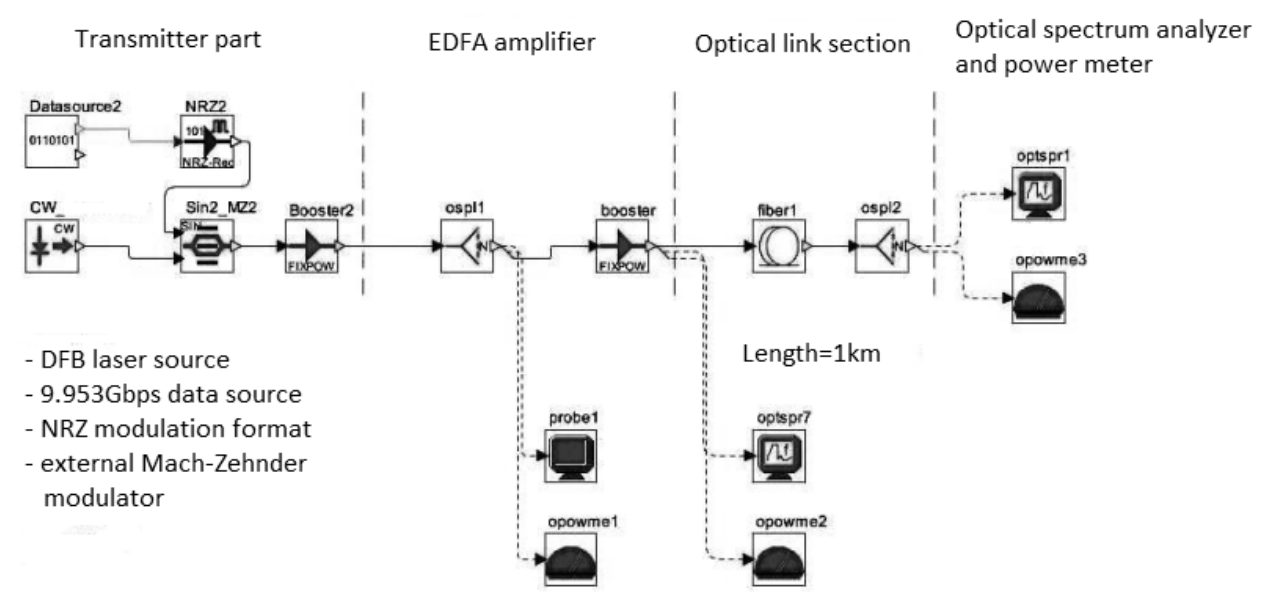

Fig. 4. Experimental and simulation schemes.

During its propagation in an OF the pulsed signal is subjected to the SPM action, which leads to a nonlinear phase shift and appearance of sidebands in the optical spectrum of the signal or generation of spectral components. From the spectral picture, which can be observed with the help of optical spectrum analyzer 
(OSA), it is possible to derive a relationship between the initial frequency and the generated $1^{\text {st }}$ order side frequency intensities in the form [5]:

$$
\frac{I_{0}}{I_{1}}=\frac{J_{0}^{2}\left(\phi_{S P M} / 2\right)+J_{1}^{2}\left(\phi_{S P M} / 2\right)}{J_{1}^{2}\left(\phi_{S P M} / 2\right)+J_{2}^{2}\left(\phi_{S P M} / 2\right)},
$$

where $I_{0}$ and $I_{1}$ are the intensities of the zeroth and $1^{\text {st }}$ order harmonics;

$J_{n}$ are the $n$-th order Bessel functions.

Ignoring dispersion, the nonlinear phase shift $\phi_{S P M}$ can be expressed as a function of $I_{0} / I_{1}$ from Eq. (12). The variables in this equation can be measured easily enough with the help of the scheme described above. The measurements were taken for short OFs only, so that the OF losses and dispersion do not affect the measurement results [7]. P-SPM measuring method requires a relatively low average power that is concentrated in very short pulses supplied by a laser pulse source with high peak intensity. The spectral extension for the Gaussian pulses under the P-SPM influence can be calculated as

$$
\frac{(\Delta \omega)_{\text {out }}}{(\Delta \omega)_{\text {in }}}=\sqrt{1+\frac{4}{3 \sqrt{3}}\left(\gamma \cdot P \cdot L_{\text {eff }}\right)^{2}},
$$

where $\Delta \omega$ is the mean-square value of the spectral width;

$P \quad$ is the peak power.

Performing the measurements by this method it is possible to obtain highly precise results. However, to achieve this, detailed information is needed about the shape of the introduced pulse; also, it is necessary to know the fiber's dispersion and attenuation, since these parameters can significantly affect the output spectrum. To describe results mathematically we used the least squares method [12].

Figure 5 shows the output spectrum according to the input optical signal power for the P-SPM measurement scheme. The input signal power is changing from

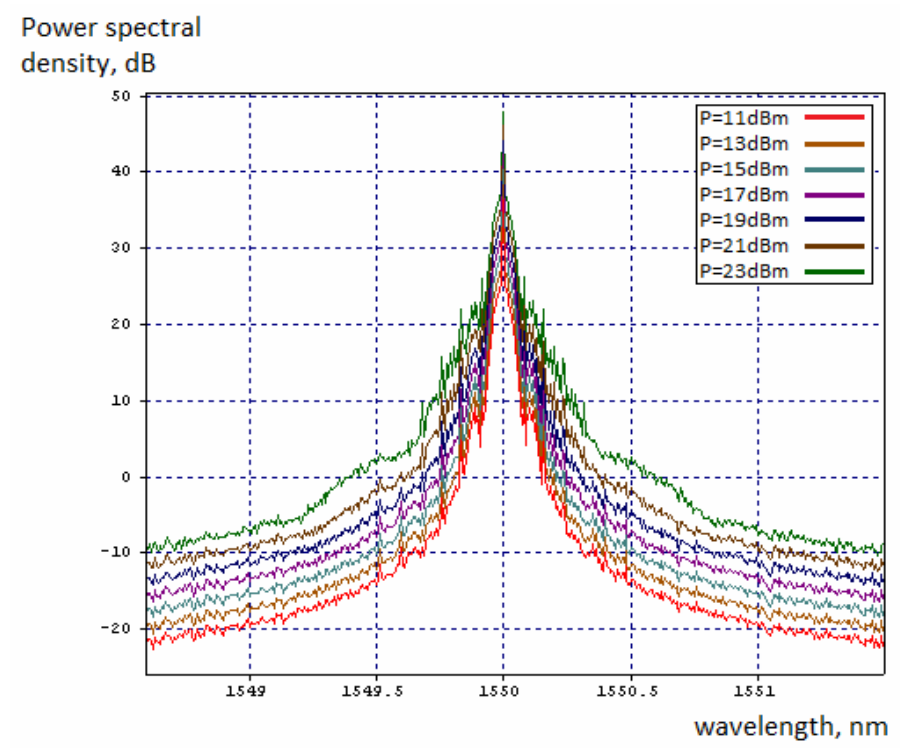

Fig. 5. Output spectra for P-SPM measurement scheme and G652 D fiber. 
$11 \mathrm{dBm}$ to $23 \mathrm{dBm}$ with a step of $4 \mathrm{dBm}$. The results are obtained using simulation software OptSim 5.2. A signal spectrum widening due to SPM effect enhancement with optical power is clearly seen.

Measurement results for CW-SPM and P-SPM methods with G.652 D and G655 C fibers are shown in Fig. $6 a-d$.

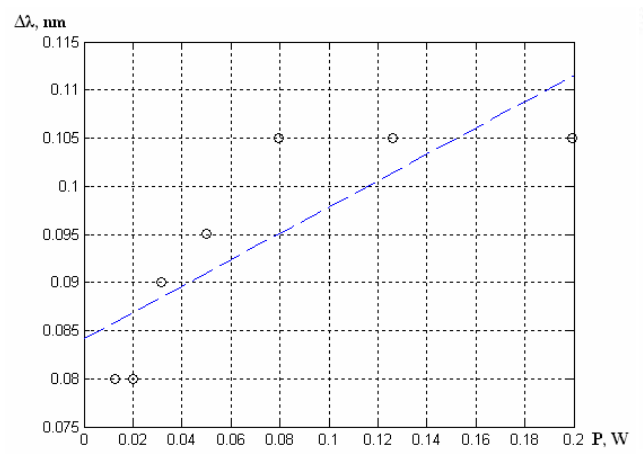

Fig. 6. a) Measurement results with CW-SPM for G652 D type fiber.

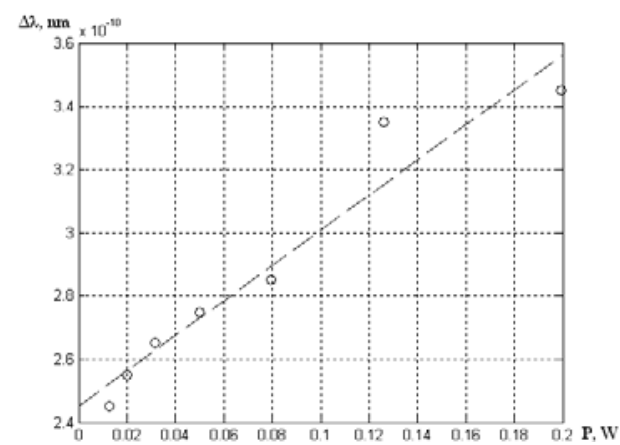

Fig. 6. c) Measurement results with P-SPM for G652 D type fiber.

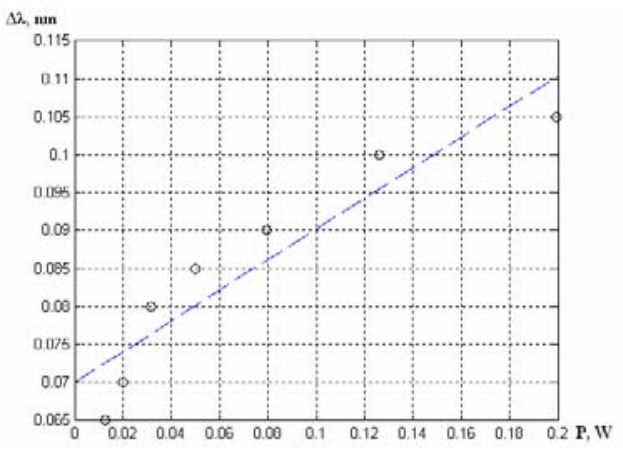

Fig..6.b) Measurement results with CW-SPM for $\mathrm{G} 655 \mathrm{C}$ type fiber.

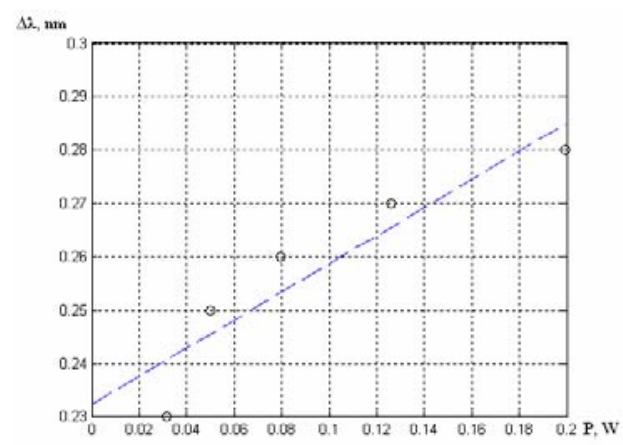

Fig. 6. d) Measurement results with P-SPM for $\mathrm{G} 655 \mathrm{C}$ type fiber.

The calculated $n_{2}$ and $\gamma$ values for the CW-SPM and P-SPM schemes with the two fibers are given in Table 3.

Table 3

Experimental and simulation results

\begin{tabular}{|c|c|c|c|c|}
\hline \multirow{2}{*}{$\begin{array}{c}\text { Fiber } \\
\text { type }\end{array}$} & \multicolumn{2}{|c|}{ Experimental results } & \multicolumn{2}{c|}{ OptSim 5.2 simulation results } \\
\cline { 2 - 5 } & \multicolumn{2}{|c|}{ CW-SPM } & \multicolumn{2}{c|}{ CW-SPM } \\
\cline { 2 - 5 } & $\gamma,(1 / \mathrm{W})$ & $n_{2},\left(\mathrm{~m}^{2} / \mathrm{W}\right)$ & $\gamma,(1 / \mathrm{W})$ & $n_{2},\left(\mathrm{~m}^{2} / \mathrm{W}\right)$ \\
\hline G652 D & $1.37 \cdot 10^{-10}$ & $0.89 \cdot 10^{-20}$ & $1.46 \cdot 10^{-10}$ & $0.95 \cdot 10^{-20}$ \\
\hline G655 C & $2.02 \cdot 10^{-10}$ & $1.11 \cdot 10^{-20}$ & $1.23 \cdot 10^{-10}$ & $0.68 \cdot 10^{-20}$ \\
\hline \multirow{2}{*}{$\begin{array}{c}\text { Fiber } \\
\text { type }\end{array}$} & \multicolumn{2}{|c|}{$\mathrm{P}-\mathrm{SPM}$} & \multicolumn{2}{c|}{$\mathrm{P}-\mathrm{SPM}$} \\
\cline { 2 - 5 } & $\gamma,(1 / \mathrm{W})$ & $n_{2},\left(\mathrm{~m}^{2} / \mathrm{W}\right)$ & $\gamma,(1 / \mathrm{W})$ & $n_{2},\left(\mathrm{~m}^{2} / \mathrm{W}\right)$ \\
\hline G652 D & $2.36 \cdot 10^{-10}$ & $1.53 \cdot 10^{-20}$ & $3.48 \cdot 10^{-10}$ & $2.26 \cdot 10^{-20}$ \\
\hline G655 C & $5.26 \cdot 10^{-10}$ & $2.89 \cdot 10^{-20}$ & $4.88 \cdot 10^{-10}$ & $2.68 \cdot 10^{-20}$ \\
\hline
\end{tabular}




\section{EVALUATION OF MEASUREMENT ERRORS}

The fiber effective area and the nonlinear coefficient can be determined through indirect measurements only, i.e. measuring definite optical parameters and afterwards calculating them. This means that the end result contains all measurement errors of the primary parameters. First of all we will consider the fiber effective area.

As concerns $A_{\text {eff }}$, the primary characteristic is the optical radiation power distribution at the far-field. To determine this characteristic we used optical wavelength \& power meter (resolution $\pm 0.05 \mathrm{~dB}$ for the wavelength range 1520$1580 \mathrm{~nm}$ ) and a micro-positioner (the least step $0.156 \mu \mathrm{m}$ ). Comparison of the influence exerted by these two parameters on the final result shows that most of errors are due to the insufficient precision of the micro-positioner step size ( $\sim 5.64 \%$ as shown by calculations). Such precision is unacceptable for our measurements; to improve it, more advanced equipment is needed, especially for the fibers with complex refractive index profiles (such as non-zero dispersion shifted fibers (NZDSF)).

Nonlinear coefficient measurements are based on the comparison of optical signal input and output spectra. The SPM effect can be seen in Fig. 5 as spectrum expansion. To obtain a signal spectrum at the OF output an optical spectrum analyzer (the wavelength precision $\leq 3 \%$, the level measurement accuracy $\leq 0.4 \mathrm{bdB}$ at $1550 \mathrm{~nm}$ ) was used. Through spectral measurements we can change linearly the spectral width at different power levels. The nonlinear coefficient can be found through determination of this linear relationship or linear function angular coefficient. Figure 7 shows the worst case scenario, when one half of the error bars are pointed to one direction and the other - to the opposite, thus achieving the greatest influence on the linearly approximating function angular coefficient. This is done to find out the maximum possible error due to the imperfect measurement equipment.

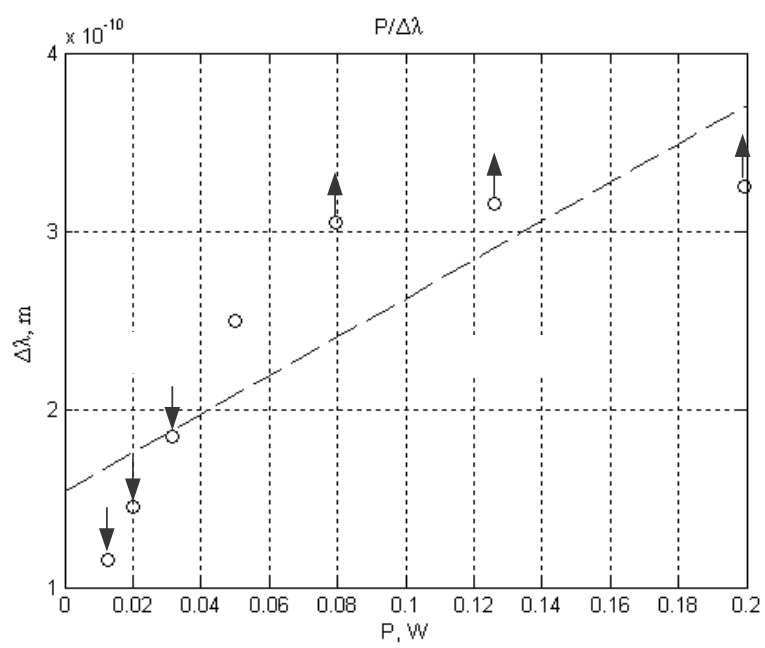

Fig.7. The error interval worst case scenario

In this case (G655C type fiber and P-SPM method) the nonlinear coefficient changes from $5.26 \cdot 10^{-10}$ to $5.79 \cdot 10^{-10}$, which means a $10 \%$ inaccuracy of the 
results. Obviously, the probability of the worst case scenario is insignificant. If these error bars are pointed at random directions, the uncertainty of calculated results is below $5 \%$.

\section{DISCUSSION AND CONCLUSIONS}

The computer simulations and experiments with the use of P-SPM and CW SPM measuring techniques allow for the statement that in the method with a laser source of pulses the NOE influence on the propagation of optical signal is noticeably greater, since there is a pronounced pulse spectrum extension due to the shift in the nonlinear phase; in turn, in the case of a CW laser source in the spectrum, infinitesimal additional spectral components arise. This means that the SPM gives rise to considerable pulse extension, and, consequently, also to a decrease in the data transmission speed. Both measurement methods produce similar uncertainty of the results.

With the help of CW-SPM and P-SPM measuring methods the following parameters have been determined experimentally: nonlinear coefficient $\gamma$ and nonlinear refractive index $n_{2}$; accordingly, $\gamma$ is calculated to be in the range $1.37 \cdot 10^{-10}-5.26 \cdot 10^{-10} 1 / \mathrm{W}$, whereas $n_{2}-$ in the range $0.89 \cdot 10^{-20}-2.89 \cdot 10^{-20} \mathrm{~m}^{2} / \mathrm{W}$ depending on the fiber type. It is established that as the laser power increases these coefficients decrease while the nonlinear phase shift $\varphi_{S P M}$ increases. As seen from the results, G652 D fibers have a smaller variation in the nonlinear coefficient values at different measurement methods as compared with $\mathrm{G} 655 \mathrm{C}$ fibers. For the G652 D type fiber the $n_{2}$ value is stable in the limits from $0.89 \cdot 10^{-20}$ (CW-SPM method) to $1.53 \cdot 10^{-20} \mathrm{~m}^{2} / \mathrm{W}$ (P-SPM method).

The similarities revealed at comparison of the experimental and simulation results are as follows.

For the G652 D type fiber and CW-SPM method the results almost coincide (difference 6\%). The other case (G655 C type fiber and CW-SPM method) shows larger differences - up to $40 \%$. For more detailed studies it is planned to perform multiple measurements to derive statistics on the precision of each measurement method.

When using EDFA amplifiers in the measurements it should be taken into account that increase in the input signal power above the noise power at the amplifier's input will lead to changes in amplification. To avoid this, the input signal should be smaller than $-45 \mathrm{dBm}$.

The results obtained could be used at planning and implementation of the fiber optic transmission systems, and especially of high-speed local area networks (LANs) where these types of fiber are required.

\section{Acknowledgment}

This work has been supported by the European Social Fund within the project „Support for the implementation of doctoral studies at Riga Technical University" and by the European Regional Development Fund within the project Nr. 2010/0270/2DP/2.1.1.1.0/10/APIA/VIAA/002. 


\title{
REFERENCES
}

1. Agrawal, G. P. (2001). Nonlinear Fiber Optics. San Diego: Academic Press, 452 p.

2. Porins, J., Ozols, A., Ivanovs, G., \& Eimuss, J. (2004). Nonlinear optical losses in telecommunication fibres. Latv. J. Phys. Tec. Sci., (4), 48-57.

3. Lamminpää, A., Hieta, T., Envall, J., \& Ikonen, E. (2007). Reliable determination of optical fiber nonlinearity using dispersion simulations and improved power measurements. J. of Lightwave Technology, 25 (2), 527-532.

4. Lamminpää, A., Niemi, T., Ikonen, E., Martilla, P., \& Ludvigsen, H. (2005). Effects of dispersion on nonlinearity measurement of optical fibers. Optical Fiber Technology, 11, 278-285.

5. Vinegoni, C., Wegmuller, M., \& Gisin, N. (2001). Interlaboratory measurements of the nonlinear coefficient of standard SMF and DSF fibers using an interferometric method and an SPM based cw dual-frequency method. Proc OFMC.

6. Gilmore, M. (2008). Understanding OM1, OM2, OM3, OS1, OS2 Fiber. The Fibreoptic Industry Association, p 3.

7. Porinšs, J., Ivanovs, Ģ., \& Supe, A. (2010). Measurements of Nonlinear Coefficient in OS2 Optical Fiber. Electronics and Electrical Engineering, 101 (5), 53-56.

8. Bjarklev, A. (1993). Optical Fiber Amplifiers: Design and System Application. London: Artech House.

9. Drapela, T.J. (2000). Effective Area and Nonlinear Coefficient Measurements of Single-Mode Fibers: Recent Interlaboratory Comparisons. National Institute of Standards and Technology, 5 pp.

10. Pattojoshi, P., \& Hosain, S.I. (1998). Single-parameter variational approximations for linear and nonlinear effects in single-mode fibers: a comparative study. Microwave and Optical Technology Letters, 18 (1). 63-73.

11. Namihira, Y, Miyagi, K., Kaneshima, K., Tadakuma, M., Vinegoni, C., Pietra, G., \& Kawanami, K.A (2002). Comparison of six techniques for nonlinear coefficient measurements of various single mode optical fibers. $12^{\text {th }}$ Symposium on Optical Fiber Measurements, Boulder, 15-19.

12. Le Derickson, D., \& Muller, M. (2008) Digital Communications Test and Measurement. Boston: Personal Education, 953 p.

\section{OPTISKO ŠKIEDRU NELINEARITĀTES NOVĒRTĒJUMA METODES, IZMANTOJOT SIGNĀLA FĀZES PAŠMODULĀCIJAS EFEKTU}

\author{
A. Supe, J. Poriňš \\ Kopsavilku ms
}

Šajā pētījumā dots salīdzinājums starp divām nelineārā koeficienta mērījumu metodēm: nepārtraukta optiskā starojuma fãzes pašmodulācijas (CW-SPM) un impulsveida optiskā signāla fãzes pašmodulācijas mērījumu metode (P-SPM). Balstoties uz eksperimentāliem un ar datorsimulācijas programmu OptSim 5.2 iegūtiem rezultātiem, ir aprēķinātas optiskās šķiedras nelineārā koeficienta $n_{2}$ vērtības. G652 D tipa optiskajai šķiedrai, tās ir robežās no $n_{2}=0,89 \cdot 10^{-20}(\mathrm{CW}$ SPM mērījumu metode) līdz $n_{2}=1,53 \cdot 10^{-20} \mathrm{~m}^{2} / \mathrm{W}$ (P-SPM mērījumu metode). Savukārt G655 C šķiedrai $n_{2}$ ir robežās no $1,11 \cdot 10^{-20}$ (CW-SPM mērījumu metode) līdz $2,89 \cdot 10^{-20} \mathrm{~m}^{2} / \mathrm{W}$ (P-SPM mērījumu metode). Iegūtie rezultāti var tikt izmantoti, plānojot un ieviešot augsta datu pārraides ātruma optiskās pārraides sistēmas, pielietojot šajā pētījumā apskatītās optiskās šķiedras.

12.12.2011. 